\title{
PERSAMAAN OPERASIONAL DALAM PROSES LAMINASI BAHAN KEMASAN
}

\author{
LUSI ZAFRIANA \\ Fakultas Teknik Industri Universitas Kartini (UNKAR) Surabaya \\ E-mail: lusizafriana@yahoo.com
}

\begin{abstract}
ABSTRAK
Pelapisan lembaran plastik seperti kertas untuk makanan, tas plastik, dan sebagainya sekarang dibutuhkan bagi industri. Untuk mendapatkan material terlaminasi, bentuk proses pelapisan dengan kaca film. Persamaan operasional dalam proses laminasi perlu untuk ditemukan sehingga proses laminasi dapat disesuaikan dengan kebutuhan. Masalah seperti itu yang biasanya tidak bisa diselesaikan oleh produsen. Dengan menggunakan prinsip keseimbangan massa, persamaan dapat ditemukan. Dengan pengumpulan data, kita dapat menghitung konstanta dari persamaan dan juga nilai RPM yang akan digunakan untuk menentukan film pelapisan yang dibutuhkan sesuai kebutuhan.
\end{abstract}

Kata kunci: proses laminasi, prinsip keseimbangan massa, ketebalan film pelapis

\begin{abstract}
Plastick sheet coated like paper for food, bag packaged plastic, etc now is needed for industry. To find material it laminated, it form still in coated laminated process with plastic film. An operational equation in the laminated process need to be founded so that its laminated process can be adjusted with the assigned order. That is usually problem that is not be solved by producers. By using mass balanced principles, the equation can be founded. By using data collected, we can calculate constanta of the equation and also RPM display value that will be used to determine thick of coated film needed for the width film as ordered.
\end{abstract}

Key words: laminated process, mass balanced principles, thick of coated film

\section{PENDAHULUAN}

Proses laminasi adalah proses pemberian lapisan film plastik pada suatu bahan lembaran, misalnya kertas kraft, tenun plastik, dll, sehingga diperolehlah bahan itu kedap air, uap ataupun udara. Beberapa produk kemasan tenun plastik yang pada awalnya memakai inner liner yang berupa kantong film plastik sebagai kantong dalaman pada karung tenun plastik guna mencegah kebocoran bahan atau kontaminasi udara/uap air atau air, sekarang bergeser ke karung tenun plastik yang dilaminasi.
Proses laminasi terjadi karena adanya aliran bahan polipropilen cair di dalam barrel extruder yang dikompresi oleh screw dan keluar melalui bibir die, kemudian melekat pada lembaran bahan dengan lebar tertentu. Suatu screw pendorong bahan di dalam silinder barrel didisain dengan cara tertentu agar pada saat pendorongan bahan itu terjadi pula proses mixing dan pressing bahan menuju T-die.

Untuk suatu mesin laminasi tertentu, jumlah bahan (dalam gram/menit atau $\mathrm{cm}^{3} /$ menit) akan tertentu pula, namun akan tergantung pada

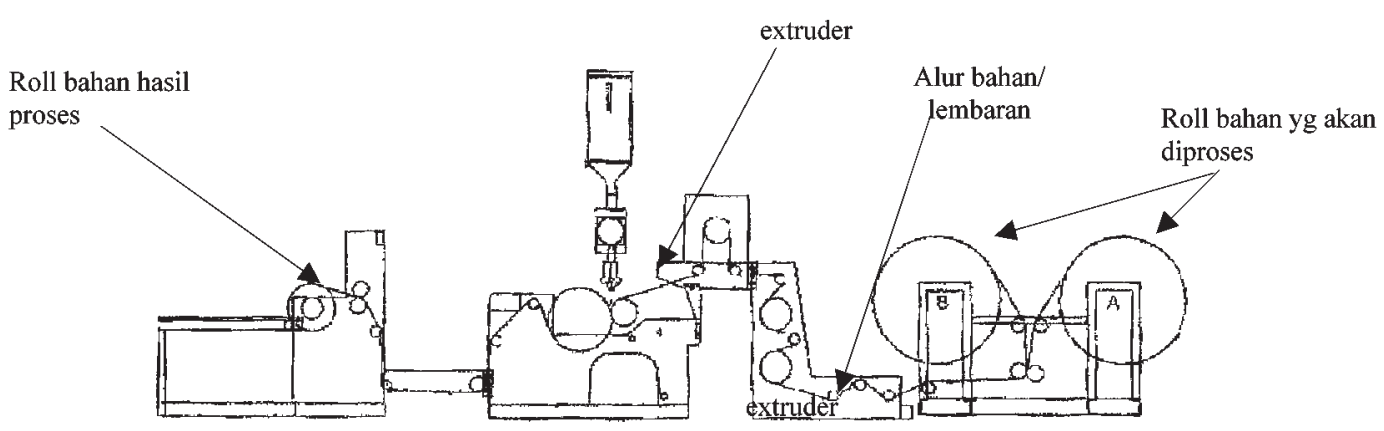

Gambar 1. Sketsa Mesin dan Proses Laminasi 


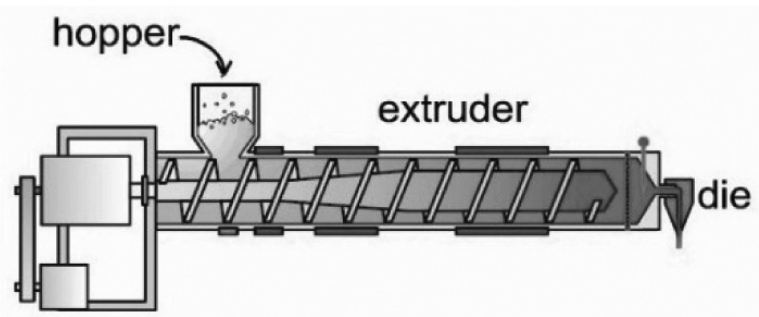

Gambar 2. Sketsa Sederhana dari Screw Extruder

kecepatan screw (dalam putaran per menit atau RPM). Laju terdorongnya kuantitas bahan ini harus diketahui untuk keperluan setting dan pengendalian tebal laminasi sesuai yang diinginkan. Sayangnya pihak produsen mesin tidak menginformasikan kuantitas itu sehingga pengguna sendiri yang harus mencarinya.

Penelitian ini bertujuan untuk memaparkan langkah pencaritahuan kuantitas bahan yang terdorong tersebut per satuan waktu. Pertama dibahas prinsip fisis matematis yang akan mendasari proses pelapisan bahan itu. Kedua, berdasarkan persamaan matematika yang diperoleh, dilakukan perancangan percobaan untuk memperoleh data guna penghitungan kuantitas yang dicari. Ketiga, dilakukan pembahasan terhadap hasil yang diperoleh, dan penggunaannya dalam proses laminasi.

\section{METODE}

\section{Prinsip Neraca Bahan}

Bahan yang terdorong oleh screw yang berputar dalam silinder barrel akan muncul keluar melalui celah sempit dan lebar yang disebut T-die dengan wujud lembaran film (lapisan tipis) dan akan turun mengenai dan menempel pada lembaran bahan yang akan dilaminasi (substrat: kertas kraft, tenun plastik, dll). Secara mudah bisa dipahami bahwa jumlah bahan yang muncul melalui T-die akan sama dengan jumlah bahan yang menempel pada substrat.

Jumlah bahan yang terdorong oleh screw (g/min) $=\mathrm{RPM}_{\text {screw }} \times \mathrm{V}_{\text {ruas ulir screw }} \times \rho_{\text {cair }}$

Jumlah bahan yang menempel pada bahan (g/min) $=\mathrm{LS}_{\text {bahan }} \times \mathrm{T}_{\text {film }} \times \mathrm{L}_{\text {film }} \times \rho_{\text {padat }}$

Dengan menyamakan kedua suku kanan, diperoleh:

$$
\begin{aligned}
& \mathrm{RPM}_{\text {screw }} \times \mathrm{V}_{\text {ruas ulir scew }} \times \rho_{\text {cair }}=\mathrm{LS}_{\text {bahan }} \times \mathrm{T}_{\text {film }} \times \mathrm{L}_{\text {film }} \times \\
& \rho_{\text {padat }}
\end{aligned}
$$

Maka:

$$
\begin{aligned}
\mathrm{T}_{\text {film }} & =\frac{\mathrm{RPM}_{\text {screw }} \times \mathrm{V}_{\text {ruas ulir screw }} \times \rho_{\text {cair }}}{\mathrm{LS}_{\text {bahan }} \times \mathrm{L}_{\text {film }} \times \rho_{\text {padat }}} \\
& =\frac{\mathrm{V}_{\text {ruas ulir screw }} \times \rho_{\text {cair }}}{\rho_{\text {padat }}} \times \frac{\mathrm{RPM}_{\text {screw }}}{\mathrm{LS}_{\text {bahan }} \times \mathrm{L}_{\text {film }}} \ldots \ldots . . \\
\mathrm{T}_{\text {film }} & =\frac{\mathrm{V}_{\text {ruas ulir screw }} \times \rho_{\text {cair }}}{\rho_{\text {padat }}} \times \frac{\mathrm{RPM}_{\text {screw }}}{\mathrm{LS}_{\text {bahan }} \times \mathrm{L}_{\text {film }}} \\
& =\mathrm{K} \times \frac{\mathrm{RPM}}{\mathrm{LS}_{\text {bahan }} \times \mathrm{L}_{\text {film }}}
\end{aligned}
$$

Pada persamaan (5) telah didefinisikan konstanta $\mathbf{K}$, di mana:

$$
\mathbf{K}=\frac{\mathrm{V}_{\text {ruas ulir screw }} \times \rho_{\text {cair }}}{\rho_{\text {padat }}}
$$

Persamaan (6) bisa diubah menjadi:

Jumlah gram bahan yang terdorong

$\mathbf{K}=\underline{\text { karena screw berputar satu putaran }}$

Sehingga:

$$
\rho_{\text {padat }}
$$

Jumlah bahan yang keluar lewat

$\mathbf{K}=$ $\mathrm{T}$ - die (gram/menit)

$$
\rho_{\text {padat }}
$$

dengan: $\rho_{\text {padat }}=\rho_{\text {polipropilen }}=$ berat jenis dari propilene $(0,928 \mathrm{~g} / \mathrm{cc})$

Jika putaran screw, RPM screw $_{\text {dalam putaran/ }}$ menit; linespeed, $\mathrm{LS}_{\text {bahan }}$ dalam meter/menit; lebar film, $\mathrm{L}_{\text {film }}$ dalam $\mathrm{cm}$; tebal lapisan film, $\mathrm{T}_{\text {film }}$ dalam micron; dan $\mathrm{K}$ dalam $\mathrm{cm}^{3} /$ putaran, maka:

$$
\frac{\mathrm{RPM}_{\text {screw }}}{\mathrm{LS}_{\text {bahan }}} \times \frac{\mathrm{L}_{\text {film }} \times \mathrm{T}_{\text {film }}}{100 \times \mathbf{K}}
$$

Angka 100 pada penyebut persamaan (9) muncul dari penyesuaian satuan micron ke $\mathrm{cm}$ dan meter ke $\mathrm{cm}$. Persamaan (9) disebut persamaan operasional proses laminasi. Dengan persamaan tersebut, setting tebal lapisan film yang diinginkan untuk lebar film tertentu bisa diatur dengan menghitung dan menset rasio $\mathbf{R P M} / \mathbf{L S}$.

\section{Perancangan Pengumpulan Data}

Dengan persamaan (8) nilai K bisa ditentukan dengan melakukan percobaan. Mesin extruder 
(seperti pada Gambar 2) dijalankan pada kecepatan putar screw tertentu dan kemudian setelah pengeluaran film melalui T-die terjadi secara stabil (tidak terputus-putus), film tersebut ditampung tiap selama 5 menit.

Tabel 1. Form Pengamatan Data

\begin{tabular}{|c|c|c|c|c|c|}
\hline \multirow{2}{*}{ RPM } & \multicolumn{5}{|c|}{ Gram/menit bahan } \\
\hline & Data-1 & Data-2 & Data-3 & Data-4 & Rata-rata \\
\hline \multicolumn{6}{|l|}{10} \\
\hline \multicolumn{6}{|l|}{20} \\
\hline \multicolumn{6}{|l|}{30} \\
\hline \multicolumn{6}{|l|}{35} \\
\hline \multicolumn{6}{|l|}{40} \\
\hline \multicolumn{6}{|l|}{45} \\
\hline 50 & & & & & \\
\hline
\end{tabular}

\section{RPM Display vs RPM Tacho}

RPM yang berpengaruh pada proses extrusion pastilah RPM screw yang sebenarnya, bukan menurut display. Putaran screw yang sebenarnya bisa diketahui dengan memasangkan tachometer. Ternyata ada perbedaan nilai antara tachometer dangan display. Tabel berikut menunjukkan perbedaan itu.

Tabel 2. Nilai RPM yang Ditunjukkan oleh Tachometer dan Display

\begin{tabular}{cccc}
\hline $\begin{array}{c}\text { RPM } \\
\text { Tacho }\end{array}$ & $\begin{array}{c}\text { RPM } \\
\text { Display }\end{array}$ & $\begin{array}{c}\text { RPM Display } \\
\text { Hitungan }\end{array}$ & Selisih Absolut \\
\hline 12,2 & 10 & 10,20 & 0,20 \\
22,9 & 20 & 19,46 & 0,54 \\
34,9 & 30 & 29,65 & 0,35 \\
41,1 & 35 & 34,92 & 0,08 \\
46,9 & 40 & 39,85 & 0,15 \\
53,2 & 45 & 45,20 & 0,20 \\
58,5 & 50 & 49,70 & 0,30 \\
\hline Selisih absolut rata-rata & & 0,26 \\
\hline \multicolumn{2}{l}{ Persen selisih rata-rata }
\end{tabular}

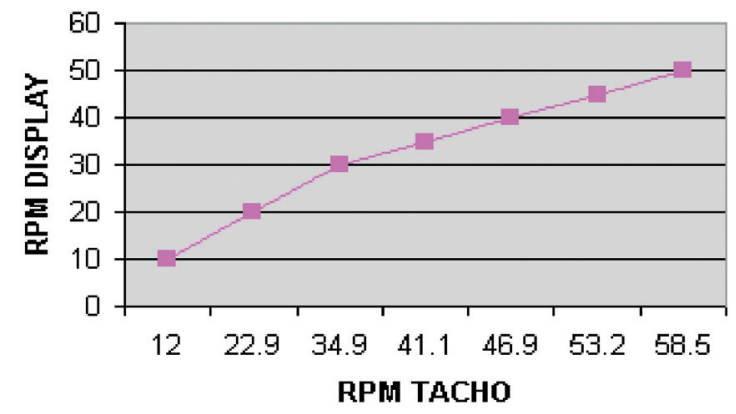

Gambar 3. Grafik antara RPM Tacho vs RPM Display
Setelah dilinerisasikan diperoleh hubungan sebagai berikut:

$\mathrm{RPM}$ Display $=0,85 \times \mathrm{RPM}$ Tacho

Rasio RPM Display dengan RPM Tacho nyaris konstan, sehingga untuk penggunaan pada proses bisa dipakai RPM Display.

\section{Pengumpulan Data}

Setelah dilakukan pengumpulan data sesuai dengan yang direncanakan, diperoleh data seperti Tabel 3 berikut.

Tabel 3. Data Jumlah Bahan (gram) yang Keluar Melalui T-Die Selama 5 Menit

\begin{tabular}{crrrrc}
\hline $\begin{array}{l}\text { RPM } \\
\text { Display }\end{array}$ & Data-1 & Data-2 & Data-3 & Data-4 & Rata-rata \\
\hline 10 & 1323,5 & 1289,0 & 1135 & 1200,0 & 1236,9 \\
20 & 2131,5 & 2032,5 & 1923,5 & 1920,0 & 2001,9 \\
30 & 2936,5 & 2775,0 & 2658,5 & 2630,0 & 2750,0 \\
35 & 3405,0 & 3157,5 & 3093,5 & 3076,5 & 3183,1 \\
40 & 3755,0 & 3884,0 & 3491,5 & 3527,5 & 3664,5 \\
45 & 4266,0 & 4177,5 & 3964,0 & 3905,0 & 4078,1 \\
50 & 4741,5 & 4532,5 & 4441,0 & 4372,5 & 4521,9 \\
\hline
\end{tabular}

\section{HASIL DAN PEMBAHASAN}

Dengan persamaan (8), nilai K untuk setiap nilai RPM bisa dihitung. Tabel 3 berikut menampilkan hasilnya.

Tabel 3. Hasil Penghitungan Nilai K pada Beberapa Nilai RPM

\begin{tabular}{llllllll}
\hline $\mathrm{RPM}$ (display) & 10 & 20 & 30 & 35 & 40 & 45 & 50 \\
$\mathrm{~K}\left(\mathrm{~cm}^{3} / \mathrm{put}\right)$ & 26,7 & 21,5 & 19,8 & 19,6 & 19,7 & 19,5 & 19,5 \\
\hline
\end{tabular}

Jika data pada Tabel 3 diplotkan secara grafik, maka tren dari Nilai K terhadap Nilai RPM akan nampak dengan lebih jelas. Pada kecepatan putaran

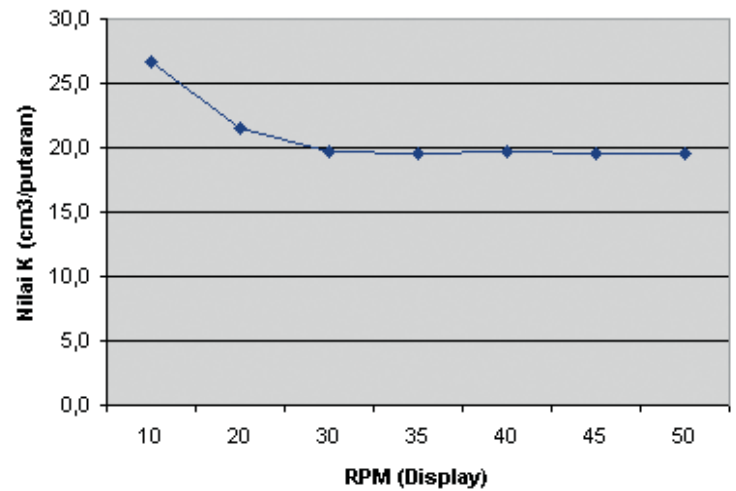

Gambar 4. Grafik Nilai K terhadap Kecepatan Putaran Screw 
screw 30 RPM ke atas, Nilai K akan cenderung konstan sebesar 19,6 $\mathrm{cm}^{3} /$ putaran screw.

Dengan diperolehnya nilai $K$, maka operasionalisasi proses laminasi bisa dilakukan. Sebagai contoh akan diproses laminasi roll woven yang lebarnya $45 \mathrm{~cm}$ (maka lebar film $48 \mathrm{~cm}$ ) dengan tebal 25 micron. Agar delivery tercapai ditetapkan linespeed (LS) sebesar 65 meter/menit. Kecepatan screw yang diperlukan agar tercapai ketebalan laminasi tersebut dihitung dengan persamaan operasional (9) dengan $\mathrm{K}=19,6 \mathrm{~cm} 3 /$ put), sebagai berikut.

$\frac{\mathrm{RPM}_{\text {screw }}}{\mathrm{LS}_{\text {bahan }}}=\frac{(48 \mathrm{~cm}) \times(25 \mathrm{micron})}{100 \times\left(19,6 \mathrm{~cm}^{3} / \text { put }\right.}=0,612$ putaran $/ \mathrm{m}$

Maka pada LS sebesar $65 \mathrm{~m} /$ menit diperlukan kecepatan screw $0,612 \times 65=39,8$ put/menit. Jika mesin diset pada nilai-nilai kecepatan tersebut, maka diperoleh ketebalan lapisan film pada bahan sesuai dengan yang diminta, 25 micron. Gambar 4 memperlihatkan bahwa ada dua daerah nilai $\mathrm{K}$ yaitu untuk RPM Display 10-30, dan 30-50. Pada kecepatan putaran screw antara 30 hingga $50 \mathrm{RPM}$, nilai $\mathrm{K}$ nyaris sama $19,6 \mathrm{~cm}^{3} /$ putaran, sedangkan pada kecepatan putaran screw di bawah 30 RPM, nilai $\mathrm{K}$ seperti merupakan fungsi lengkung menurun seturut naiknya RPM. Jika disepakati operasi laminasi hanya dijalankan pada RPM 30-50, maka nilai $\mathrm{K}$ adalah $19,6 \mathrm{~cm}^{3} /$ putaran.

\section{SIMPULAN}

Proses laminasi dijalankan pada RPM Display antara 30-50 maka nilai K adalah 19,6 cm3/putaran, Perencanaan proses laminasi dimulai dengan menetapkan lebar film $(\mathrm{cm})$ dan tebal laminasi (micron). Kemudian dipilih linespeed tertentu (m/ menit) dan dihitung besarnya kecepatan putaran screw yang harus diset.

\section{PUSTAKA}

Himmelblau, D.M, and Riggs, J.B., 2003. Basic Principles and Calculations in Chemical Engineering, International Edition, seventh Edition, Prentice Hall International.

Stewart, J. 2000. Kalkulus Universitas, Balai Pustaka, Jakarta

Taha, H.A 1996. Operations Research: An Introduction, sixth Edition, Prentice Hall, New York.

Tri Polyta Indonesia, Tbk. 2008. Buku Saku Plastik, Klaten.

Y. Pochet and L.A. Wolsey. 1993. Lot sizing with constant batches: Formulation and valid inequalities, Mathematics of Operations Research 18, 767-785. 